\title{
Hereditary sensory and autonomic neuropathy due to TECPR2 mutation
}

INSERM

\section{Source}

INSERM. (1999). Orphanet: an online rare disease and orphan drug data base. Hereditary sensory and autonomic neuropathy due to TECPR2 mutation. ORPHA:320385

Hereditary sensory and autonomic neuropathy due to TECPR2 mutation is a rare genetic peripheral neuropathy characterized by early hypotonia evolving to spastic paraparesis, areflexia, decreased pain and temperature sensitivity, autonomic neuropathy, gastroesophageal reflux disease, recurrent pneumonia and respiratory problems. Patients also have intellectual disability and dysmorphic features, including mild brachycephalic microcephaly, short broad neck, low anterior hairline and coarse face. 